\title{
Prescribing naloxone for opioid overdose intervention
}

\author{
Robert B Dunne*,1 \\ ${ }^{1}$ Department of Emergency Medicine, Wayne State University School of Medicine, Detroit, MI 48202, USA \\ *Author for correspondence: rkdunne@wayne.edu
}

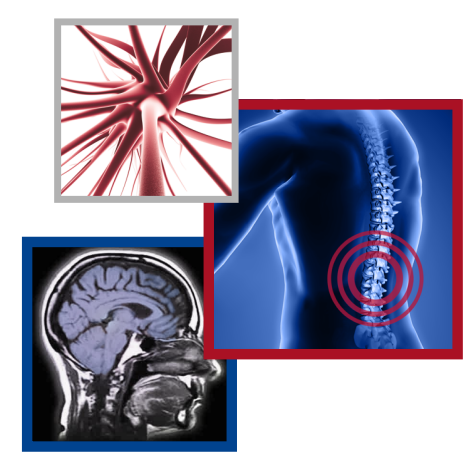

\section{Practice points}

- The public-health response to the opioid crisis requires a multifaceted approach that includes guidelines to effect changes in opioid prescribing, interventions to prevent or treat opioid abuse and dependence, and strategies to diminish the harmful effects of opioid misuse.

- Numerous guidelines have advocated use of the opioid antagonist naloxone as a harm-reduction strategy.

- Two naloxone products that include instructions for use by personnel without medical training have been approved by the US FDA for community use: an intranasal spray and an autoinjector for intramuscular or subcutaneous use.

- In primary care and pain medicine, coprescription of naloxone could be considered for patients with opioid prescriptions exceeding a threshold daily dose or patients with other risk factors for overdose.

- Although there are potential opportunities to expand naloxone use in many settings, evidence from current literature suggests these are often missed or underexploited.

- Academic detailing interventions could be used to increase naloxone prescribing for patients receiving opioid prescriptions in a primary care setting.

- Naloxone could be prescribed at discharge from the emergency department to individuals at risk of opioid overdose.

- Wider use of naloxone may also include law enforcement personnel, addiction treatment facilities and individuals newly released from incarceration.

- Most states now permit naloxone prescriptions to be written for third parties (e.g., family or friends, staff of organizations providing services to individuals at risk of overdose).

To provide an update on prescription of naloxone as a harm-reduction strategy, PubMed was searched to identify publications relevant to naloxone prescribing for reversal of opioid overdose. Opportunities now exist to expand naloxone use, although evidence suggests these are often missed or underexploited. The US FDA has approved an intranasal naloxone spray and an autoinjector naloxone formulation for community use. Effective use of naloxone in community settings requires screening to identify patients at risk of opioid overdose, discussing naloxone use with patients and their relatives, and providing appropriate training. The tools exist to expand the use of naloxone more widely into the community, thereby creating an opportunity to reduce opioid overdose fatalities.

First draft submitted: 28 November 2017; Accepted for publication: 23 February 2018; Published online: 18 April 2018

Keywords: drug overdose • harm-reduction strategy • intranasal drug administration • naloxone - opioid antagonists

The USA, and to a lesser extent some European countries and Australia, is experiencing an opioid epidemic [1,2]. During the past two decades, opioid sales, admissions for opioid overdoses and opioid-related deaths have dramatically increased [2-4]. Since 2000, the incidence of opioid overdoses has tripled, and deaths from opioid overdose (both prescription analgesics and heroin) have increased by 200\% in the USA [4]. In 2015, opioids accounted for 33,091 deaths, corresponding to $63 \%$ of all drug overdose deaths [5]. This epidemic has been driven by a number of factors, principally increasing rates of opioid prescriptions - and a corresponding rise in nonmedical use of prescription opioids; a recent increase in deaths from illicit opioid overdose, largely driven by heroin use; and a sharp rise in fentanyl-related overdose deaths, particularly involving illicitly manufactured fentanyl $[1,2,4,6]$. The public-health response to this epidemic of opioid overdoses requires a multifaceted approach that includes 
- Addiction medicine specialists

- Upon discharge from inpatient treatment

- During outpatient treatment

- Department of corrections

- Upon release from incarceration

- Emergency departments

- Pain medicine specialists

- Primary care providers

- Pharmacy based (varies by state)

- Collaborative practice agreement

- Standing medication order

- Protocol order

- Pharmacist prescriptive authority

guidelines to effect changes in opioid prescribing, interventions to prevent or treat opioid abuse and dependence, and strategies to diminish the harmful effects of opioid misuse [3,7].

Naloxone is a competitive opioid antagonist that has been in clinical use since 1967 to reverse respiratory depression caused by opioid overdose [8,9]. The continuing epidemic of opioid-related fatalities has led to the increasing use of naloxone in community-based harm-reduction strategies [8-11]. Whereas naloxone is normally given by injection in the healthcare setting, intranasal formulations are generally used in the community [9] and studies have shown that intranasal naloxone can be used successfully by nonmedical first responders and other laypersons to reverse opioid overdose and prevent overdose-related deaths [12-14]. Initially, naloxone for community use consisted of improvised intranasal kits, which contained a prefilled syringe of naloxone (formulated for injection) that could be modified for intranasal administration by attaching an atomizer [15,16]. Subsequently, two naloxone combination (drug/device) products that include instructions for use for personnel without medical training have been approved by the US FDA for community use: an intranasal spray (NARCAN ${ }^{\circledR}$; Adapt Pharma, Inc., PA, USA) $[17,18]$ and an autoinjector for intramuscular or subcutaneous use $\left(\mathrm{EVZIO}^{\circledR}\right.$; Kaléo, Inc., VA, USA) [16]. Recent literature was reviewed to provide an update on prescribing naloxone as a harm-reduction strategy, with the aim of encouraging expanded access to naloxone for individuals at risk of opioid overdose.

\section{Methodology}

PubMed searches covering the period from January 2000 to October 2017 were performed using the search terms ('prescription' OR 'prescribing' OR 'prescribed') AND 'naloxone'. Searches were limited to English language publications. The abstracts of retrieved articles were reviewed to identify publications relevant to the prescription of naloxone for the reversal of opioid overdose.

\section{Settings for naloxone prescribing}

The principal channels for naloxone distribution are hospitals, clinics and retail pharmacies. Key settings for prescription of naloxone for community use include emergency departments, physician offices and addiction treatment facilities (see Box 1) [8-11,19-26]. Other potential avenues include prescription upon release from incarceration and prescription by pharmacists [19,24-26].

\section{Naloxone prescribing in the emergency department}

Many patients with opioid exposure, either due to legitimate use of prescription analgesia or illicit opioid use, present to emergency departments. In the USA, between 2008 and 2011, more than one million emergency visits occurred each year for drug poisoning, and $14.0 \%$ of visits for unintentional overdose were opioid-related [27]. The national rate of opioid-related emergency department visits nearly doubled between 2005 and 2014 [28]. Data in 2010 from the Nationwide Emergency Department Sample show that $67.8 \%$ of emergency department visits for opioid-related overdose involved prescription opioids and $16.1 \%$ involved heroin [29]. Chronic opioid use is an important driver of emergency department visits. For example, in a study using administrative claims data (both Medicaid and commercially insured patients), approximately $25.0 \%$ of patients receiving chronic ( $\geq 90$ days) opioid therapy had an emergency department visit within the first 12 months of opioid use [30]. 
A population-based study of two US states (California and Florida) found that $52.8 \%$ of emergency department visits for opioid overdose resulted in hospitalization, and $10.0 \%$ involved a near-fatal event (i.e., an overdose necessitating mechanical ventilation) [31]. Furthermore, the risk of near-fatal events was significantly increased among patients with frequent $(\geq 2)$ visits to the emergency department, compared with those with only a single visit (odds ratio $=2.27 ; 95 \% \mathrm{CI}=1.94-2.66 ; \mathrm{p}<0.001$ ) [31]. This finding is consistent with a case-control study of statewide data (New York) that found that approximately $40 \%$ of patients who subsequently died of an unintentional prescription drug overdose had multiple prior emergency department visits [32].

Despite the large number of emergency department visits for opioid overdose [27,29], and the fact that opioids are commonly prescribed in emergency departments for pain control [33], prescribing or dispensing of naloxone in this setting is relatively uncommon. A survey of opioid-related policies in New England emergency departments found that only $12 \%$ of departments would prescribe naloxone for patients at risk of opioid overdose after discharge, and the adoption of other opioid-related policies was variable (use a screening tool, 18\%; notify primary care providers of opioid prescription, $41 \%$; refer to recovery resources, $70 \%$; access Prescription Drug Monitoring Program, 78\%) [34]. Similarly, in a Web-based survey of 200 emergency department physicians, respondents generally expressed a willingness to adopt opioid harm-reduction strategies, but only $1.7 \%$ reported previously prescribing naloxone and only $10.3 \%$ had referred patients to a naloxone distribution program [35]. In another Web-based survey of 459 Canadian emergency department physicians, although $86 \%$ of respondents were willing to prescribe naloxone to patients at risk of opioid overdose, they identified limited time in the clinical encounter, lack of institutional supports and lack of knowledge and training as barriers to implementation of communitybased opioid overdose education and naloxone distribution programs [36]. Additional barriers to naloxone access may include financial burden (as prices for some naloxone products have increased in recent years) [37], formulary restrictions and variations among state laws regulating prescribing [38,39]. Another important barrier in emergency departments is federal law that prohibits charging for naloxone dispensed in this setting unless there is an outpatient pharmacy within the medical facility.

Emergency department-based naloxone distribution is widely accepted by patients. In one study, $68.2 \%$ of patients receiving opioid therapy at a daily dose of $\geq 100$ morphine milligram equivalent (MME; equivalent, e.g., to 20 tablets of hydrocodone $5 \mathrm{mg}$ /acetaminophen $300 \mathrm{mg}, \sim 12$ tablets of oxycodone $5 \mathrm{mg} /$ acetaminophen $325 \mathrm{mg}$ and $\sim 2$ tablets of extended-release oxycodone $30 \mathrm{mg}[40]$ ) and those with self-reported opioid use (or a prescription for medications commonly used in the treatment of opioid addiction) accepted a naloxone kit and training when this was offered [41].

\section{Naloxone prescribing in outpatient settings}

Primary care providers commonly provide healthcare for patients receiving opioid analgesia and patients with illicit opioid use, and thus represent a potentially valuable avenue for naloxone use in the community. Discussing naloxone with primary care patients provides the opportunity to highlight the risks associated with opioid use and offer a harm-reduction strategy. However, the available evidence suggests that although primary care providers generally have favorable attitudes toward the use of naloxone, a relatively low percentage has prescribed naloxone to their patients [42]. In a survey of 97 internal medicine residents at an urban US academic medical center, $86.5 \%$ agreed that naloxone is effective for reducing opioid overdose deaths, and a similar percentage (92.1\%) did not believe that naloxone prescription would promote increased opioid use [42]. However, only $46.8 \%$ had ever discussed overdose risk and prevention with patients and only $15 \%$ had previously prescribed naloxone for community use. This lack of prescribing may be due to a lack of confidence in their ability to identify patients at risk of overdose and prescribe naloxone appropriately, as only $16 \%$ of respondents indicated that they knew how to prescribe the drug. These findings are consistent with those of a survey of 448 general practitioners in Ireland, in which $66.1 \%$ of general practitioners indicated that they were in favor of using naloxone in the community, but only $31.6 \%$ were prepared to take part in such a project [43].

By contrast, naloxone prescribing rates are much higher at clinics participating in an overdose prevention program [44]. In a survey of 111 primary care providers offering naloxone prescriptions to patients receiving longterm opioids as part of a US public health department program, $79.3 \%$ of respondents had prescribed naloxone since the program began, and $99.1 \%$ reported being likely to prescribe naloxone in the future [44]. Most respondents reported that they would prescribe naloxone for patients on either high-dose ( $>20 \mathrm{MME}$ per day) or low-dose ( $<20$ MME per day) opioid therapy (97.7 and 59.8\%, respectively), and in patients without a known history of overdose $(80.7 \%)$ or substance use disorder (73.6\%). Nationally, Symphony Health Solutions data (extracted July 
2017) showed 101,863,027 prescriptions for opioids and 149,259 prescriptions for naloxone (ratio, 682:1) during the first 6 months of 2017.

\section{Academic detailing programs in primary care}

Academic detailing programs use one-on-one educational interventions to deliver evidence-based information to healthcare providers within their own practices. This approach has been used in a number of countries, including Canada and the UK, and has delivered significant behavioral change, for example, in increasing smoking cessation efforts [45]. Such programs may, therefore, increase naloxone prescribing by primary care providers.

An academic detailing program in San Francisco provided 40 primary care providers with written information on prescribing controlled substances, prescription drug-monitoring programs and the effectiveness and cost effectiveness of naloxone, accompanied by a 5-60-min discussion tailored to the interests of the individual provider [45]. The number of naloxone prescriptions was increased to a significantly greater extent in providers who received the detailing intervention, compared with those who did not ( $\mathrm{p}=0.01)$, and at follow-up, 12 of 24 detailed providers (50.0\%) had written at least one naloxone prescription.

To reduce deaths from opioid overdose among US veterans, the US Veterans Health Administration instituted the first nationwide Opioid Overdose Education and Naloxone Distribution (OEND) program in 2014 [46]. The effect of supplementing this program with academic detailing was examined in a retrospective study, in which academic detailing was provided to 750 of 3313 providers (22.6\%), almost $91 \%$ of whom were in primary care (90.9\%) [46]. Naloxone prescription rates were three-times greater after 12 months and seven-times greater after 24 months for providers who received academic detailing, compared with those who did not. However, given the low base rates for naloxone prescribing before the detailing intervention, even such striking increases may have benefited only a modest number of patients.

\section{Naloxone coprescription programs}

Naloxone coprescription programs have been developed for both primary care [20,21] and pain medicine [22] practices. In one study [20], naloxone was prescribed in $38.2 \%$ of 1985 patients receiving long-term opioid therapy: patients receiving higher opioid doses and those with an opioid-related emergency department visit within the previous 12 months were more likely to be prescribed naloxone. After 12 months, patients who had received a naloxone prescription had made $63 \%$ fewer opioid-related emergency department visits per month than those who had not.

The available evidence suggests that patients receiving opioids for pain relief generally have positive attitudes to naloxone coprescription. In a study of 208 patients receiving opioid treatment for chronic noncancer-related pain, $60.6 \%$ of participants thought that offering naloxone to opioid-treated patients was a 'good' or 'very good idea'; relatively few would be 'a little' $(10.1 \%)$ or 'very' $(3.4 \%)$ offended if a health professional thought they needed naloxone [47]. Similarly, in an interview study of 60 patients ( $87 \%$ were prescribed opioids for pain) who received naloxone prescriptions in a primary care clinic, most participants had a positive $(56.7 \%)$ or neutral $(21.7 \%)$ response to being offered naloxone; $82 \%$ of participants successfully filled a naloxone prescription and $36.7 \%$ reported positive behavioral changes (e.g., safer opioid dosing or safer timing of dose) after receiving naloxone [48].

Coprescription of naloxone is mandated by law in Vermont (as of 1 July 2017) for patients receiving an opioid prescription that exceeds $90 \mathrm{MME}$ per day or patients receiving an opioid prescription (any dose) concurrent with a prescription for a benzodiazepine. On 15 March 2017, the Virginia Board of Medicine issued regulations requiring coprescription of naloxone with opioids for patients with risk factors, specifically prior overdose, substance abuse, opioid dose in excess of $120 \mathrm{MME}$ or concomitant benzodiazepine prescription. In the 2 months after the Virginia regulation went into effect, naloxone prescribing increased to approximately one naloxone prescription for every 45 opioid prescriptions compared with the national average (in the late May 2017) of approximately one naloxone prescription for every 570 opioid prescriptions (Symphony Health Solutions data).

\section{Naloxone prescribing in addiction treatment settings}

Although the ultimate goals of treatment for patients with opioid addiction are treating substance dependence and preventing substance misuse, harm-reduction strategies are essential intermediate steps [49]. Together with syringe-exchange programs and opioid substitution, naloxone distribution is a valuable harm-reduction strategy for opioid users [49], but objections to prescribing naloxone for opioid users have been raised based primarily on concerns that naloxone does not address the underlying addiction and may actually encourage opioid use (either 
because an antidote is available or by precipitating withdrawal) [49-52]. However, concerns that prescribing naloxone will result in increased opioid use are refuted by the available data $[49,51,53]$.

The potential impact of a naloxone prescription program for opioid users is highlighted by the experience gained in the Drug Overdose Prevention and Education program, which was established in 2003 in collaboration with the San Francisco Department of Public Health and is one of the oldest naloxone prescription programs in the USA [54]. Overall, $11 \%$ of individuals who were prescribed naloxone reported using the drug during an overdose event, and $83 \%$ of these overdose events were reversed with naloxone.

A recent study has investigated outcomes after providing naloxone overdose reversal kits to patients enrolling in medication-assisted treatment of opioid use disorders [23]. A total of 244 patients were enrolled and received education about opioid overdose and the use of the naloxone autoinjector kit. Of 215 evaluable patients, 31 either experienced or witnessed at least one opioid overdose episode. Interviews of these patients indicated that 39 opioid overdoses had been reversed with naloxone.

\section{Other avenues for naloxone prescribing}

Correctional facilities

Opioid users are at increased risk of overdose after a period of abstinence, such as after institutionalization or incarceration [55]. In a US study of former inmates, released between 1999 and 2003, the risk of death within the first 2 weeks after release was 12.7-times that of the general population, and drug overdose was the leading cause of death [56]. A follow-up study of inmates released between 1999 and 2009 found a tenfold increased risk of overdose in former inmates, compared with the general population; opioids were involved in $58.6 \%$ of overdose deaths, of which pharmaceutical opioids accounted for $40.5 \%$ [57].

An educational program on opioid overdose prevention and naloxone administration designed specifically for inmates before release has been developed and is currently in use in a number of correctional facilities [24]. In what is believed to be the first reported cases of naloxone self-administration to prevent fatal overdose, two former inmates who had undergone this program successfully self-administered intranasal naloxone to treat opioid overdose within 3 weeks of release [25]. In an initiative piloted in 2016 and expanded in January 2017, inmates released from Baltimore area (and other Maryland county) jails are provided naloxone training and two doses of the FDA-approved intranasal naloxone as part of a state-run program [26].

\section{Pharmacy-based naloxone dispensing}

Pharmacy-based naloxone dispensing offers an alternative to the traditional prescription process in which a prescription is provided by a licensed provider (e.g., physician, physician assistant, nurse practitioner) to a specific patient. In recent years, 40 states have passed legislation whereby patients and caregivers can receive naloxone from a pharmacy without having a prescription from a healthcare provider (e.g., via standing orders) [58]. These programs are designed to expand community access to naloxone [19,59]. Standing orders, the most common mechanism for pharmacy-based naloxone dispensing, are prescriptions written by a physician or other prescriber that authorize naloxone to be dispensed to any person who meets specific criteria (typically individuals at risk of opioid overdose, in the case of naloxone standing orders), rather than to a specific patient [38,39]. In addition to pharmacy-based naloxone dispensing, some states permit dispensing by nonmedical professionals [38]. In some states, statewide standing orders, issued by a government official such as the Physician General, authorize naloxone dispensing by pharmacists throughout the state [39]. Details about pharmacy-based models vary by state and, in addition to standing medication orders, may include collaborative pharmacy practice agreements, protocol orders and pharmacist prescriptive authority (see Table 1) [19]. Many pharmacy-based models permit third-party prescribing of naloxone, for example, to a friend or family member rather than to the person actually at risk of overdose. This practice is legal in most states, in recognition of the fact that such third parties may be more likely to raise concerns about opioid-related risks and are likely potential witnesses of an overdose [39].

\section{Guidelines \& policy statements on naloxone prescribing}

The CDC and the WHO along with many additional national and international organizations have issued guidelines or policy statements on naloxone prescribing (see Table 2) [40,60-64]. In addition, a number of state and municipal departments of health have also developed prescribing guidelines for naloxone.

Coprescription of naloxone with opioids is endorsed by large insurers, and an assessment of the legal risk associated with prescribing or dispensing naloxone concluded that coprescribing naloxone for a patient at risk 


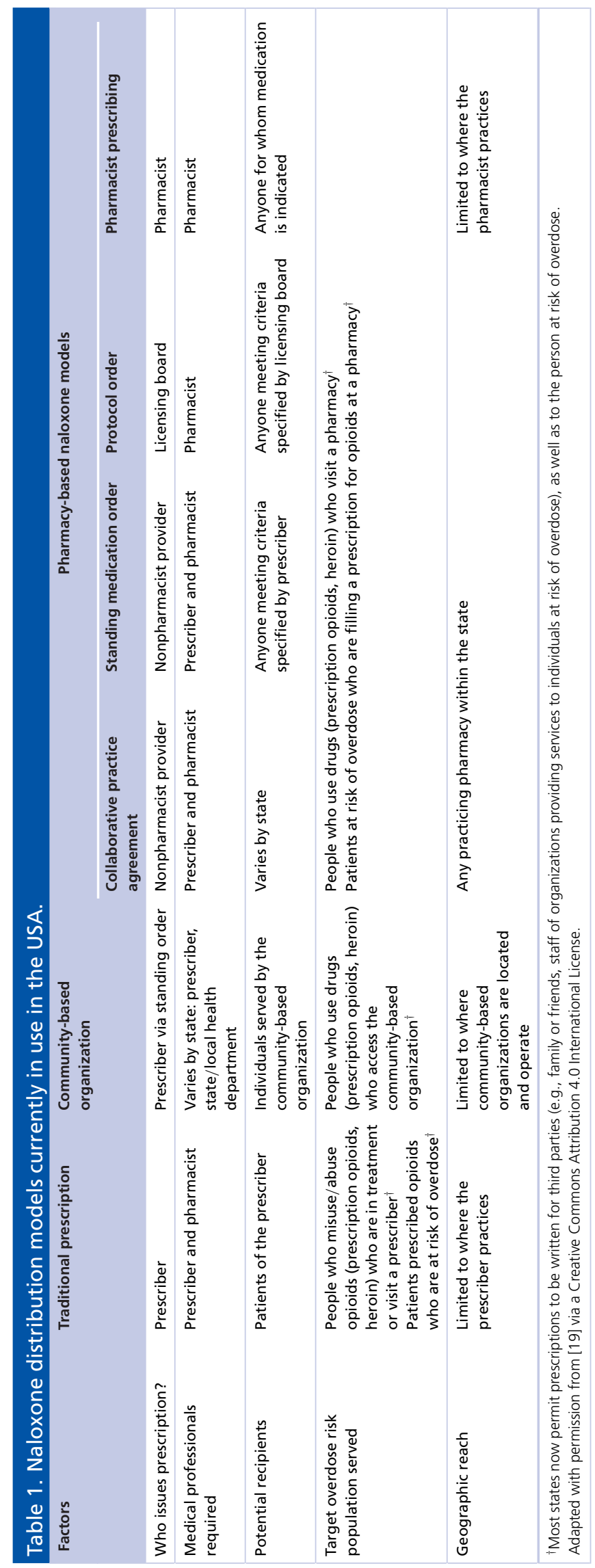




\begin{tabular}{|c|c|c|c|}
\hline Organization & Guidelines/policy & Key content & Ref. \\
\hline WHO & Community Management of Opioid Overdose & $\begin{array}{l}\text { Contains recommendations on: } \\
\text { - Naloxone distribution to people likely to witness an overdose } \\
\text { - Appropriate formulations and doses of naloxone for community use }\end{array}$ & [60] \\
\hline CDC & Guideline for Prescribing Opioids for Chronic Pain & $\begin{array}{l}\text { Clinicians should: } \\
\text { - Prescribe the lowest effective opioid dosage, use caution increasing to } \\
\geq 50 \mathrm{MME} \text { per day and avoid } \geq 90 \mathrm{MME} \text { per day (unless carefully justified) } \\
\text { - Consider offering naloxone when risk factors are present (i.e., history of } \\
\text { overdose or substance use disorder, opioid dose } \geq 50 \mathrm{MME} \text { per day, concurrent } \\
\text { benzodiazepine use) }\end{array}$ & [40] \\
\hline SAMHSA & Opioid Overdose Prevention Toolkit & $\begin{array}{l}\text { - Summarizes factors to consider before prescribing opioids, use of PDMPs and } \\
\text { patient education/monitoring } \\
\text { - Providers should consider prescribing naloxone along with the initial opioid } \\
\text { prescription }\end{array}$ & [61] \\
\hline AAPM & $\begin{array}{l}\text { Coprescribing of Naloxone in Conjunction with } \\
\text { Opioid Therapy }\end{array}$ & $\begin{array}{l}\text { Prescribers of opioid therapy should: } \\
\text { - Fully assess overdose risk } \\
\text { - Discuss risk factors with patients/caregivers } \\
\text { - Offer prescription of an FDA-approved naloxone product }\end{array}$ & [62] \\
\hline ASAM & $\begin{array}{l}\text { Public Policy Statement on the Use of Naloxone } \\
\text { for the Prevention of Drug Overdose Deaths }\end{array}$ & $\begin{array}{l}\text { - Supports broadened accessibility to naloxone for community use } \\
\text { - Encourages coprescription of naloxone with long-acting opioids and } \\
\text { significant total opioid dosage } \\
\text { - Recommends training for naloxone recipients in overdose detection and } \\
\text { response (including naloxone administration) }\end{array}$ & [63] \\
\hline ASAM & $\begin{array}{l}\text { The National Practice Guideline for the Use of } \\
\text { Medications in the Treatment of Addiction } \\
\text { Involving Opioid Use }\end{array}$ & $\begin{array}{l}\text { - Discusses naloxone in the context of other medications used in the treatment } \\
\text { of opioid addiction } \\
\text { - Prescriptions for naloxone should be provided to patients being treated for } \\
\text { opioid use disorder and their family members/significant others }\end{array}$ & [64] \\
\hline
\end{tabular}

AAPM: American Academy of Pain Management; ASAM: American Society of Addiction Medicine; MME: Morphine milligram equivalent; PDMP: Prescription Drug Monitoring Program; SAMHSA: Substance Abuse and Mental Health Services Administration.

of overdose is a 'reasonable and prudent clinical and legal decision' and does not increase the provider's liability risk [65].

\section{Identifying appropriate patients}

The identification of patients at risk of opioid overdose is a key challenge in expanding access to naloxone [21]. As might be anticipated, studies of patients on opioid therapy for acute or chronic pain have shown that higher prescribed opioid doses are associated with an increased risk of overdose [66-68]. In addition, the use of long-acting opioids is associated with a significantly increased risk of overdose, compared with short-acting preparations, particularly during the first 2 weeks of treatment [69]. Other factors associated with increased risk of opioid overdose include concomitant benzodiazepine use, co-morbid medical conditions, co-morbid mental disorders and co-morbid substance use disorder [68,70,71].

Having identified individuals at risk of opioid overdose, it might be particularly effective to target OEND interventions to their social network, members of which may be most likely to witness an opioid overdose. However, it should be noted that such individuals may not be interacting with community OEND programs [72].

\section{Clinical best practices in naloxone prescribing}

The successful implementation of naloxone prescribing programs requires attention to a number of aspects of clinical practice. Education of providers on all strategies for opioid management should be a priority, and academic detailing programs should be expanded to all providers.

\section{Screening for opioid overdose risk}

A number of validated instruments are available to assess the risk of opioid overdose. These include the Opioid Risk Tool, a 5-item measure designed for use with patients in primary care settings [73], and two self-report instruments, the revised Screener and Opioid Assessment for Patients with Pain [74] and the Simple Screening Instrument for Substance Abuse [75]. At this writing, no published data favor the use of one instrument over another in routine clinical practice. Asking about drug use during social history-taking should be part of any encounter with a patient. In addition, a review of the patient's current medications is essential to assess risk. 


\section{Electronic health record alerts}

The use of electronic alerts may facilitate effective naloxone prescribing. In a study within an academic health system comprising two hospitals with emergency departments, outpatient clinics, infusion centers and pharmacies, the mean number of naloxone prescriptions per month increased from 4.5 at baseline to 46 during the 3 months after implementing an OEND program with electronic health record alerts [76]. More than half (53\%) of these prescriptions were for unapproved (improvised) intranasal naloxone, $43 \%$ were for intramuscular naloxone via standard syringe and needle and 4\% were for the FDA-approved autoinjector [76]. However, 'alert fatigue' may be one limitation to using electronic alerts to increase naloxone prescriptions in patients receiving opioids. Appropriate thresholds should be developed for these communications, particularly with high-risk combinations of medications.

\section{Discussing naloxone with patients}

The importance of carefully discussing the use of naloxone with patients or their families or friends cannot be overemphasized. The results of an interview study of 24 patients prescribed high-dose opioid therapy for chronic noncancer-related pain suggested that framing naloxone as relevant for worst-case scenarios (analogous to keeping a fire extinguisher on hand or wearing a seatbelt) was a nonjudgmental, empowering approach that could potentially increase patient acceptance [77].

\section{Training in naloxone use for patients \& members of their social network}

There is evidence that correct administration of naloxone is more likely with FDA-approved products (intranasal spray and intramuscular/subcutaneous autoinjector) than with unapproved (improvised) intranasal kits [16,18]. Dissemination of naloxone to interested community members and training on its use through a community intervention initiative should be considered. Using local data to target 'hot spots' in the community can help identify populations that may benefit from such services. Partnering with community groups, faith-based organizations and local health outreach services could all facilitate harm reduction.

\section{Staying current with state laws \& policies regarding naloxone prescribing}

The state laws and policies regarding naloxone prescribing have been changing rapidly in response to the epidemic of opioid overdoses [39,78]. As of May 2017, 46 states permit third-party prescription, so that naloxone can be prescribed and dispensed not only to persons at risk but also to potential bystanders [58]. Coprescription of naloxone with opioids is mandated in some states (i.e., Vermont, Virginia), and others are in the process of developing coprescribing guidelines.

\section{Conclusion}

Increased access to naloxone as a harm-reduction strategy - both for patients prescribed opioids for pain management and for those using opioids illicitly - is one component of a multifaceted approach to addressing the opioid epidemic. There are potential opportunities to prescribe naloxone to patients at risk of overdose (or to their friends or relatives) in many settings, including emergency departments, primary care office settings, addiction treatment centers, correctional facilities and (depending on the state) pharmacies. However, the current literature suggests these opportunities are often missed or underexploited. Guidelines from many US agencies or organizations consistently recommend the prescription of naloxone for patients at risk, and this approach is supported by insurers. With the FDA approval of two naloxone formulations designed for community use, the tools exist to expand the use of naloxone more widely beyond traditional healthcare settings into the community.

\section{Future perspective}

Increased provider awareness of the benefits of community-use naloxone and the availability of easy-to-use naloxone formulations will hopefully lead to increases in naloxone prescription rates. It could, therefore, be anticipated that wider use of naloxone offers the opportunity to attenuate the mortality associated with the current opioid epidemic. Based on the impact of the epidemic, it may be necessary to increase the amount of naloxone dispensed by an order of magnitude or more to make an impact on the rate of opioid-related overdose fatalities. Providers may effect change by screening patients for opioid overdose risk, becoming more familiar with available naloxone formulations, discussing naloxone with patients in a nonjudgmental fashion and staying abreast of state laws and policies related to naloxone prescribing. Additional naloxone products for community use (including instantly disintegrating buccal tablets [79] and additional intranasal spray formulations [80,81]) are currently in development and, if approved by 
the FDA, will provide further treatment options. Regulatory approval for over-the-counter purchase, which would remove a significant barrier to naloxone availability, seems unlikely in the near term, highlighting the importance of state laws and regulations that expand access to naloxone.

\section{Financial \& competing interests disclosure}

The author has no relevant affiliations or financial involvement with any organization or entity with a financial interest in or financial conflict with the subject matter or materials discussed in the manuscript. This includes employment, consultancies, honoraria, stock ownership or options, expert testimony, grants or patents received or pending, or royalties. Background information and manuscript preparation support were provided, under the direction of RB Dunne, by Nancy Holland and Michael Shaw, Synchrony Medical Communications, LLC, PA, USA, and sponsored by Adapt Pharma, Inc., PA, USA.

\section{Open access}

This work is licensed under the Attribution-NonCommercial-NoDerivatives 4.0 Unported License. To view a copy of this license, visit http://creativecommons.org/licenses/by-nc-nd/4.0/

\section{References}

Papers of special note have been highlighted as: • of interest; $\bullet \bullet$ of considerable interest

1. Wilkerson RG, Kim HK, Windsor TA, Mareiniss DP. The opioid epidemic in the United States. Emerg. Med. Clin. North Am. 34(2), e1-e23 (2016).

2. Fischer B, Rehm J. Revisiting the 'paradigm shift' in opioid use: developments and implications 10years later. Drug Alcohol Rev. 37(Suppl. 2), S199-S202 (2017).

3. Kolodny A, Courtwright DT, Hwang CS et al. The prescription opioid and heroin crisis: a public health approach to an epidemic of addiction. Annu. Rev. Public. Health 36, 559-574 (2015).

- Presents a multifaceted framework for addressing the opioid crisis; components include prevention, treatment and harm reduction.

4. Rudd RA, Aleshire N, Zibbell JE, Gladden RM. Increases in drug and opioid overdose deaths - United States, 2000-2014. MMWR Morb. Mortal. Wkly Rep. 64(50-51), 1378-1382 (2016).

5. Rudd RA, Seth P, David F, Scholl L. Increases in drug and opioid-involved overdose deaths - United States, 2010-2015. MMWR Morb. Mortal. Wkly Rep. 65(50-51), 1445-1452 (2016).

6. Peterson AB, Gladden RM, Delcher C et al. Increases in fentanyl-related overdose deaths - Florida and Ohio, 2013-2015. MMWR Morb. Mortal. Wkly Rep. 65(33), 844-849 (2016).

7. Hawk KF, Vaca FE, D’Onofrio G. Reducing fatal opioid overdose: prevention, treatment and harm reduction strategies. Yale J. Biol. Med. 88(3), 235-245 (2015).

8. Kim HK, Nelson LS. Reducing the harm of opioid overdose with the safe use of naloxone: a pharmacologic review. Expert Opin. Drug Saf. 14(7), 1137-1146 (2015).

9. Davis C. Naloxone for Community Opioid Overdose Reversal. Center for Public Health Law Research, PA, USA (2015). http://prescribetoprevent.org/wp2015/wp-content/uploads/PHLRKnowledgeAsset_Naloxone_FINALfull_8June15.pdf

10. Compton WM, Volkow ND, Throckmorton DC, Lurie P. Expanded access to opioid overdose intervention: research, practice, and policy needs. Ann. Intern. Med. 158(1), 65-66 (2013).

11. Wheeler E, Jones TS, Gilbert MK, Davidson PJ. Opioid overdose prevention programs providing naloxone to laypersons - United States, 2014. MMWR Morb. Mortal. Wkly Rep. 64(23), 631-635 (2015).

12. Doe-Simkins M, Walley AY, Epstein A, Moyer P. Saved by the nose: bystander-administered intranasal naloxone hydrochloride for opioid overdose. Am. J. Public Health 99(5), 788-791 (2009).

13. Rando J, Broering D, Olson JE, Marco C, Evans SB. Intranasal naloxone administration by police first responders is associated with decreased opioid overdose deaths. Am. J. Emerg. Med. 33(9), 1201-1204 (2015).

14. Fisher R, O’Donnell D, Ray B, Rusyniak D. Police officers can safely and effectively administer intranasal naloxone. Prehosp. Emerg. Care 20(6), 675-680 (2016).

15. Strang J, McDonald R, Tas B, Day E. Clinical provision of improvised nasal naloxone without experimental testing and without regulatory approval: imaginative shortcut or dangerous bypass of essential safety procedures? Addiction 111(4), 574-582 (2016).

16. Edwards ET, Edwards ES, Davis E, Mulcare M, Wiklund M, Kelley G. Comparative usability study of a novel auto-injector and an intranasal system for naloxone delivery. Pain Ther. 4(1), 89-105 (2015).

17. NARCAN ${ }^{\circledR}$ (naloxone hydrochloride) nasal spray, package insert. Adapt Pharma, Inc., PA, USA (2017).

18. Krieter P, Chiang N, Gyaw $S$ et al. Pharmacokinetic properties and human use characteristics of an FDA-approved intranasal naloxone product for the treatment of opioid overdose. J. Clin. Pharmacol. 56(10), 1243-1253 (2016). 
19. Green TC, Dauria EF, Bratberg J, Davis CS, Walley AY. Orienting patients to greater opioid safety: models of community pharmacy-based naloxone. Harm Reduct. J. 12, 25 (2015).

- Summary of pharmacy-based naloxone distribution models that illustrate feasible mechanisms for expanded access to naloxone.

20. Coffin PO, Behar E, Rowe $\mathrm{C}$ et al. Nonrandomized intervention study of naloxone coprescription for primary care patients receiving long-term opioid therapy for pain. Ann. Intern. Med. 165(4), 245-252 (2016).

-. Demonstrated feasibility and benefits of naloxone coprescription in primary care clinics.

21. Wilson CG, Rodriguez F, Carrington AC, Fagan EB. Development of a targeted naloxone coprescribing program in a primary care practice. J. Am. Pharm. Assoc. 57(2S), S130-S134 (2017).

22. Takeda MY, Katzman JG, Dole E et al. Co-prescription of naloxone as a universal precautions model for patients on chronic opioid therapy-observational study. Subst. Abus. 37(4), 591-596 (2016).

23. Katzman J, Takeda MY, Bhatt SR, Balasch M, Greenberg N. Lives saved with take-home naloxone for patients in medication-assisted treatment. Addict. Med. 11(3), 1 (2017).

24. Green TC, Bowman SE, Ray M, McKenzie M, Lord SE, Rich JD. Development of an incarceration-specific overdose prevention video: staying alive on the outside. Health Educ. J. 74(5), 627-637 (2015).

25. Green TC, Ray M, Bowman SE, McKenzie M, Rich JD. Two cases of intranasal naloxone self-administration in opioid overdose. Subst. Abus. 35(2), 129-132 (2014).

26. Knezevich A. Maryland jail inmates to be trained to administer overdose drug (2016). http://www.baltimoresun.com/news/maryland/bs-md-naloxone-jails-20161225-story.html

27. Albert M, McCaig LF, Uddin S. Emergency Department Visits for Drug Poisoning: United States, 2008-2011. US Department of Health \& Human Services, MD, USA (2015).

28. Weiss AJ, Elixhauser A, Barrett ML, Steiner CA, Bailey MK, O’Malley L. Opioid-Related Inpatient Stays and Emergency Department Visits by State, 2009-2014. HCUP Statistical Brief\#219. Agency for Healthcare Research and Quality, MD, USA (2016). http://www.hcup-us.ahrq.gov/reports/statbriefs/sb219-Opioid-Hospital-Stays-ED-Visits-by-State.pdf

29. Yokell MA, Delgado MK, Zaller ND, Wang NE, McGowan SK, Green TC. Presentation of prescription and nonprescription opioid overdoses to US emergency departments. JAMA Intern. Med. 174(12), 2034-2037 (2014).

30. Braden JB, Russo J, Fan MY et al. Emergency department visits among recipients of chronic opioid therapy. Arch. Intern. Med. 170(16), 1425-1432 (2010).

31. Hasegawa K, Brown DFM, Tsugawa Y, Camargo CA Jr. Epidemiology of emergency department visits for opioid overdose: a population-based study. Mayo Clin. Proc. 89(4), 462-471 (2014).

32. Brady JE, DiMaggio CJ, Keyes KM, Doyle JJ, Richardson LD, Li G. Emergency department utilization and subsequent prescription drug overdose death. Ann. Epidemiol. 25(8), 613-619.e612 (2015).

33. Hoppe JA, Nelson LS, Perrone J et al. Opioid prescribing in a cross section of US emergency departments. Ann. Emerg. Med. 66(3), 253-259.e251 (2015).

34. Weiner SG, Raja AS, Bittner JC et al. Opioid-related policies in New England emergency departments. Acad. Emerg. Med. 23(9), 1086-1090 (2016).

35. Samuels EA, Dwyer K, Mello MJ, Baird J, Kellogg AR, Bernstein E. Emergency department-based opioid harm reduction: moving physicians from willing to doing. Acad. Emerg. Med. 23(4), 455-465 (2016).

36. Lacroix L, Thurgur L, Orkin AM, Perry JJ, Stiell IG. Emergency physicians' attitudes and perceived barriers to the implementation of take-home naloxone programs in Canadian emergency departments. CJEM 20(1), 46-52 (2017).

37. Gupta R, Shah ND, Ross JS. The rising price of naloxone - risks to efforts to stem overdose deaths. N. Engl. J. Med. 375(23), 2213-2215 (2016).

38. Davis CS, Carr D. Legal changes to increase access to naloxone for opioid overdose reversal in the United States. Drug Alcohol Depend. 157, 112-120 (2015).

39. Davis C, Carr D. State legal innovations to encourage naloxone dispensing. J. Am. Pharm. Assoc. 57(2S), S180-S184 (2017).

40. Dowell D, Haegerich TM, Chou R. CDC guideline for prescribing opioids for chronic pain - United States, 2016. JAMA 315(15), 1624-1645 (2016).

- $\quad$ CDC opioid prescribing guideline, including recommendation for naloxone coprescription.

41. Kestler A, Buxton J, Meckling G et al. Factors associated with participation in an emergency department-based take-home naloxone program for at-risk opioid users. Ann. Emerg. Med. 69(3), 340-346 (2017).

-• Results of this survey study support the provision of community-use naloxone to at-risk emergency department patients as a strategy for improving naloxone access.

42. Wilson JD, Spicyn N, Matson P, Alvanzo A, Feldman L. Internal medicine resident knowledge, attitudes, and barriers to naloxone prescription in hospital and clinic settings. Subst. Abus. 37(3), 480-487 (2016). 
43. Barry T, Klimas J, Tobin H, Egan M, Bury G. Opiate addiction and overdose: experiences, attitudes, and appetite for community naloxone provision. Br. J. Gen. Pract. 67(657), e267-e273 (2017).

44. Behar E, Rowe C, Santos GM et al. Acceptability of naloxone co-prescription among primary care providers treating patients on long-term opioid therapy for pain. J. Gen. Intern. Med. 32(3), 291-295 (2017).

45. Behar E, Rowe C, Santos GM, Santos N, Coffin PO. Academic detailing pilot for naloxone prescribing among primary care providers in San Francisco. Fam. Med. 49(2), 122-126 (2017).

46. Bounthavong M, Harvey MA, Wells DL et al. Trends in naloxone prescriptions prescribed after implementation of a National Academic Detailing Service in the Veterans Health Administration: a preliminary analysis. J. Am. Pharm. Assoc. 57(2S), S68-S72 (2017).

-. Cohort study providing evidence that academic detailing can increase naloxone prescribing rates in primary care clinics.

47. Nielsen S, Peacock A, Lintzeris N, Bruno R, Larance B, Degenhardt L. Knowledge of opioid overdose and attitudes to supply of take-home naloxone among people with chronic noncancer pain prescribed opioids. Pain Med. 19(3), 533-540 (2017).

48. Behar E, Rowe C, Santos GM, Murphy S, Coffin PO. Primary care patient experience with naloxone prescription. Ann. Fam. Med. 14(5), 431-436 (2016).

49. Bazazi AR, Zaller ND, Fu JJ, Rich JD. Preventing opiate overdose deaths: examining objections to take-home naloxone. J. Health Care Poor Underserved 21(4), 1108-1113 (2010).

50. Winograd RP, Davis CS, Niculete M, Oliva E, Martielli RP. Medical providers' knowledge and concerns about opioid overdose education and take-home naloxone rescue kits within Veterans Affairs health care medical treatment settings. Subst. Abus. 38(2), 135-140 (2017).

51. Kim D, Irwin KS, Khoshnood K. Expanded access to naloxone: options for critical response to the epidemic of opioid overdose mortality. Am. J. Public Health 99(3), 402-407 (2009).

52. Seal KH, Downing M, Kral AH et al. Attitudes about prescribing take-home naloxone to injection drug users for the management of heroin overdose: a survey of street-recruited injectors in the San Francisco Bay Area. J. Urban Health 80(2), 291-301 (2003).

53. Jones JD, Campbell A, Metz VE, Comer SD. No evidence of compensatory drug use risk behavior among heroin users after receiving take-home naloxone. Addict. Behav. 71, 104-106 (2017).

54. Enteen L, Bauer J, McLean R et al. Overdose prevention and naloxone prescription for opioid users in San Francisco. J. Urban Health 87(6), 931-941 (2010).

55. Wakeman SE, Bowman SE, McKenzie M, Jeronimo A, Rich JD. Preventing death among the recently incarcerated: an argument for naloxone prescription before release. J. Addict. Dis. 28(2), 124-129 (2009).

56. Binswanger IA, Stern MF, Deyo RA et al. Release from prison - a high risk of death for former inmates. N. Engl. J. Med. 356(2), $157-165$ (2007).

57. Binswanger IA, Blatchford PJ, Mueller SR, Stern MF. Mortality after prison release: opioid overdose and other causes of death, risk factors, and time trends from 1999 to 2009. Ann. Intern. Med. 159(9), 592-600 (2013).

- Cohort study that identified opioid overdose as a leading cause of death in former prison inmates, highlighting the need for naloxone prescriptions in this population.

58. Davis C, Chang S, Carr D, Hernandez-Delgado H. Legal Interventions to Reduce Overdose Mortality: Naloxone Access and Overdose Good Samaritan Laws. The Network for Public Health Law, MN, USA (2017).

59. Morton KJ, Harrand B, Floyd CC et al. Pharmacy-based statewide naloxone distribution: a novel "top-down, bottom-up" approach. J. Am. Pharm. Assoc. 57(2S), S99-S106.e105 (2017).

60. WHO. Community Management of Opioid Overdose. Geneva, Switzerland (2014). http://www.who.int/substance_abuse/publications/management_opioid_overdose/en/

61. Substance Abuse and Mental Health Administration. Opioid Overdose Prevention Toolkit. MD, USA (2016).

62. American Academy of Pain Management. Co-prescribing of naloxone in conjunction with opioid therapy (2016). http://blog.aapainmanage.org/co-prescribing-of-naloxone-in-conjunction-with-opioid-therapy/

63. American Society of Addiction Medicine. Public Policy Statement on the Use of Naloxone for the Prevention of Drug Overdose Deaths. ASAM, MD, USA (2014).

64. American Society of Addiction Medicine. The ASAM National Practice Guideline for the Use of Medications in the Treatment of Addiction Involving Opioid Use. ASAM, MD, USA (2015). http://www.asam.org/quality-practice/guidelines-and-consensus-documents/npg

65. Davis CS, Burris S, Beletsky L, Binswanger I. Co-prescribing naloxone does not increase liability risk. Subst. Abus. 37(4), 498-500 (2016).

66. Bohnert AS, Valenstein M, Bair MJ et al. Association between opioid prescribing patterns and opioid overdose-related deaths. JAMA 305(13), 1315-1321 (2011).

67. Dunn KM, Saunders KW, Rutter CM et al. Opioid prescriptions for chronic pain and overdose: a cohort study. Ann. Intern. Med. 152(2), 85-92 (2010). 
68. Zedler B, Xie L, Wang L et al. Risk factors for serious prescription opioid-related toxicity or overdose among Veterans Health Administration patients. Pain Med. 15(11), 1911-1929 (2014).

69. Miller M, Barber CW, Leatherman S et al. Prescription opioid duration of action and the risk of unintentional overdose among patients receiving opioid therapy. JAMA Intern. Med. 175(4), 608-615 (2015).

70. Larochelle MR, Liebschutz JM, Zhang F, Ross-Degnan D, Wharam JF. Opioid prescribing after nonfatal overdose and association with repeated overdose: a cohort study. Ann. Intern. Med. 164(1), 1-9 (2016).

71. Boscarino JA, Kirchner HL, Pitcavage JM et al. Factors associated with opioid overdose: a 10-year retrospective study of patients in a large integrated health care system. Subst. Abuse Rehabil. 7, 131-141 (2016).

72. Kerensky T, Walley AY. Opioid overdose prevention and naloxone rescue kits: what we know and what we don't know. Addict. Sci. Clin. Pract. 12(1), 4 (2017).

73. Webster LR, Webster RM. Predicting aberrant behaviors in opioid-treated patients: preliminary validation of the opioid risk tool. Pain Med. 6(6), 432-442 (2005).

74. Butler SF, Fernandez K, Benoit C, Budman SH, Jamison RN. Validation of the revised Screener and Opioid Assessment for Patients with Pain (SOAPP-R). J. Pain 9(4), 360-372 (2008).

75. Substance Abuse and Mental Health Services Administration. Substance Abuse Treatment for Persons with Co-Occurring Disorders. MD, USA (2005).

76. Devries J, Rafie S, Polston G. Implementing an overdose education and naloxone distribution program in a health system. J. Am. Pharm. Assoc. 57(2S), S154-S160 (2017).

77. Mueller SR, Koester S, Glanz JM, Gardner EM, Binswanger IA. Attitudes toward naloxone prescribing in clinical settings: a qualitative study of patients prescribed high dose opioids for chronic non-cancer pain. J. Gen. Intern. Med. 32(3), 277-283 (2017).

78. Wickramatilake S, Zur J, Mulvaney-Day N, Campopiano von Klimo M, Selmi E, Harwood H. How states are tackling the opioid crisis. Public Health Rep. 132(2), 171-179 (2017).

79. Strang J, McDonald R, Alqurshi A, Royall P, Taylor D, Forbes B. Naloxone without the needle - systematic review of candidate routes for non-injectable naloxone for opioid overdose reversal. Drug Alcohol Depend. 163 16-23 (2016).

80. McDonald R, Lorch U, Woodward J et al. Pharmacokinetics of concentrated naloxone nasal spray for opioid overdose reversal: Phase I healthy volunteer study. Addiction 113(3), 484-493 (2017).

81. Tylleskar I, Skulberg AK, Nilsen T, Skarra S, Jansook P, Dale O. Pharmacokinetics of a new, nasal formulation of naloxone. Eur. J. Clin. Pharmacol. 73(5), 555-562 (2017). 